\title{
Level of asthma control and its impact on activities of daily living in asthma patients in Brazil*
}

\author{
Nível de controle da asma e seu impacto nas atividades de vida diária em \\ asmáticos no Brasil
}

\author{
Mariana Rodrigues Gazzotti, Oliver Augusto Nascimento, Federico Montealegre, \\ James Fish, José Roberto Jardim
}

\begin{abstract}
Objective: To evaluate the impact of asthma on activities of daily living and on health status in patients with controlled, partially controlled, or uncontrolled asthma in Brazil. Methods: We used data related to 400 patients in four Brazilian cities (São Paulo, Rio de Janeiro, Salvador, and Curitiba), obtained in a survey conducted throughout Latin America in 2011. All study subjects were $>12$ years of age and completed a standardized questionnaire in face-to-face interviews. The questions addressed asthma control, hospitalizations, emergency room visits, and school/work absenteeism, as well as the impact of asthma on the quality of life, sleep, and leisure. The level of asthma control was determined in accordance with the Global lnitiative for Asthma criteria. Results: Among the 400 respondents, asthma was controlled in 37 (9.3\%), partially controlled in 226 (56.5\%), and uncontrolled in 137 (34.2\%). The numbers of patients with uncontrolled or partially controlled asthma who visited the emergency room, who were hospitalized, and who missed school/work were higher than were those of patients with controlled asthma ( $p=0.001, p=0.05$, and $p=0.01$, respectively). Among those with uncontrolled asthma, the impact of the disease on activities of daily living, sleep, social activities, and normal physical exertion was greater than it was among those with controlled or partially controlled asthma $(p<0.001)$. Conclusions: In Brazil, asthma treatment should be monitored more closely in order to increase treatment adherence and, consequently, the level of asthma control, which can improve patient quality of life and minimize the negative impact of the disease.
\end{abstract}

Keywords: Asthma/epidemiology; Quality of life; Hospitalization.

\section{Resumo}

Objetivo: Avaliar o impacto da asma nas atividades da vida diária e na saúde em pacientes com asma controlada, parcialmente controlada ou não controlada no Brasil. Métodos: Foram utilizados dados de 400 pacientes de quatro cidades brasileiras (São Paulo, Rio de Janeiro, Curitiba e Salvador) obtidos em um inquérito realizado em países da América Latina em 2011. Todos os indivíduos do estudo tinham idade $>12$ anos e responderam a um questionário padronizado por meio de entrevista presencial. As questões abordavam o controle da asma, número de hospitalizações, de consultas de urgência, absenteísmo na escola/trabalho e impacto da asma na qualidade de vida, sono e lazer. 0 nível de controle da asma foi verificado segundo os critérios da Global Initiative for Asthma. Resultados: Entre 400 entrevistados, a asma estava controlada em 37 (9,3\%); parcialmente controlada, em 226 (56,5\%); e não controlada, em 137 (34,2\%). 0 número de pacientes com asma não controlada ou parcialmente controlada que apresentaram hospitalizações, visitas ao pronto-socorro e faltas na escola/trabalho foi maior do que o daqueles com asma controlada ( $p=0,001, p=0,05$ e $p=0,01$, respectivamente). Os participantes com asma não controlada apresentaram um maior impacto da doença em atividades da vida diária, sono, atividades sociais e esforço físico normal do que aqueles com asma parcialmente controlada ou controlada $(p<0,001)$. Conclusões: Medidas terapêuticas devem ser mais intensamente adotadas em nosso país para melhorar o controle da asma e estimular a aderência ao tratamento. 1sso, seguramente, proporcionará uma melhor qualidade de vida aos pacientes e uma redução do impacto negativo da doença.

Descritores: Asma/epidemiologia; Qualidade de vida; Hospitalização.

\footnotetext{
* Study carried out at the Federal University of São Paulo/Paulista School of Medicine, São Paulo, Brazil. Correspondence to: José Roberto Jardim. Rua Botucatu, 740, $3^{\circ}$ andar, Pneumologia UNIFESP/EPM, CEP 04021-032, São Paulo, SP, Brasil.

Tel. 5511 5572-4301. E-mail: jardimpneumo@gmail.com

Financial support: This study received financial support from Merck, Sharp \& Dohme Corp., which also provided the data for the study. Submitted: 15 February 2013. Accepted, after review: 12 August 2013.
} 


\section{Introduction}

Asthma is a chronic disease that is highly prevalent in Brazil. ${ }^{(1,2)}$ According to the International Study of Asthma and Allergies in Childhood, ${ }^{(3)}$ the prevalence of asthma in Brazil is approximately $20 \%$ among children (6-7 years of age) and adolescents (13-14 years of age), varying by region. This rate is one of the highest in Latin America. ${ }^{(2-4)}$ The prevalence of wheezing in the last 12 months can range from $11.8 \%$ to $30.5 \%$ among adolescents, depending on the region of Brazil. ${ }^{(3)}$ In addition to its high prevalence, asthma is the fourth leading cause of hospitalization via the Brazilian Unified Health Care System. ${ }^{(1,2)}$

The negative impact of asthma is usually estimated on the basis of mortality, number of asthma attacks, and number of hospitalizations. However, the effects of asthma can impair other important aspects, such as the quality of life and physical well-being of patients, and can affect performance at school or work. ${ }^{(5,6)} \ln 2003$, the Asthma Insights and Reality in Latin America (AIRLA) survey was carried out in order to evaluate the quality of treatment and the impact of asthma in Latin America. At the time, 52\% of the adults with asthma were found to have been to the emergency room or to have been hospitalized at least once in the previous year, demonstrating the major impact of this disease. In addition, $31 \%$ reported having missed work at least once because of an asthma attack. Likewise, asthma had an impact on children, with 58\% having missed school in the previous year. ${ }^{(7)}$

Although there is effective treatment for asthma, all these negative effects on the individual affected are triggered by poor disease control and lack of self-management training. Currently, the level of asthma control is determined in accordance with the Global Initiative for Asthma (GINA) criteria. ${ }^{(8)}$ Asthma patients are classified as having controlled, partially controlled, or uncontrolled asthma on the basis of symptoms, limitations in activities of daily living, nocturnal awakenings, use of rescue medication, and pulmonary function. ${ }^{(8)}$ In recent years, GINA has constantly updated its criteria, and the Brazilian Thoracic Association has developed guidelines for the management of asthma, ${ }^{(2)}$ both groups seeking to disseminate the concept of asthma and its treatment and control. Therefore, it is important to know what impact asthma has had on subjects affected by the disease and what their level of asthma control is so that appropriate measures can be implemented to ensure that the disease is controlled in the maximum possible number of subjects. The objective of the present study was to evaluate the impact of asthma in patients in Brazil by level of disease control.

\section{Methods}

The Latin America Asthma 1nsight and Management (LA AIM) survey was designed to assess and document patient perception of disease control, patient knowledge of the disease, and treatment modality. The survey was developed following the same methods used in the Asthma lnsight and Management (AIM) surveys conducted in the USA, Europe, Canada, Asia, and the Pacific region. The LA AIM survey was conducted in Argentina, Brazil, Mexico, Venezuela, and Puerto Rico.

Initially, 4,545 households in four Brazilian cities (São Paulo, Rio de Janeiro, Curitiba, and Salvador) were selected from a national probability sample. If there were two or more subjects with asthma in the household, one of them was randomly selected, and a home visit was scheduled over the telephone. A total of 400 patients who reported having physiciandiagnosed asthma were interviewed in person (Figure 1); the patients who were 18 years of age or older were interviewed directly, as were the parents of the adolescents between 12 and 17 years of age. The interviews lasted approximately 35 minutes. The questionnaire consisted of 53 questions that addressed five major asthma domains: symptoms; impact of asthma on life; perception of asthma control; exacerbations; and treatment/medication.

In order to evaluate the negative impact of asthma on the daily life of respondents, the questions addressed the frequency of school or work absences due to asthma, limitation in activities because of the disease, productivity levels on days when experiencing an asthma attack, and the influence of asthma on the quality of life. Respondents were also asked whether they or their children had been hospitalized or had been to the emergency room in the last 12 months and, if so, how many times. In addition, respondents were asked whether they had sought a physician for exacerbations, symptoms of worsening disease, and severe asthma attacks in the previous year. 
Respondents were required to classify their (or their child's) level of asthma control in the last four weeks and in the previous year. These levels of asthma control were subsequently compared with the GINA criteria.

All data were provided by a large pharmaceutical company, and, since we did not have any personal contact with the respondents, the Research Ethics Committee of the Federal University of São Paulo decided that protocol approval was not necessary for the present study.

In the statistical analysis, categorical variables are presented as absolute numbers and percentages, and continuous variables are presented as mean and standard deviation. The chi-square test was used for the comparison of categorical variables among the groups studied (controlled, partially controlled, and uncontrolled asthma), and ANOVA was used for the comparison of means. In order to analyze the questions related to the impact of asthma on sports, normal physical exertion, social activities, and sleep, as well as to its interference with life, each of the questions received a score ranging from 1 (high interference of asthma with daily life) to 4 (no interference of asthma), and these values are presented as mean and standard deviation. Tukey's post hoc test was used, and the level of significance was set at $p<0.05$.

\section{Results}

A total of 400 asthma patients were interviewed in four Brazilian cities: São Paulo (47.8\%), Rio de Janeiro (36.0\%), Curitiba (7.0\%), and Salvador (9.2\%). Among the 400 respondents, asthma was controlled in 37 (9.3\%), partially controlled in 226 (56.5\%), and uncontrolled in 137 (34.2\%), as determined in accordance with the GINA criteria.

The patients with controlled asthma were younger than those with uncontrolled or partially controlled asthma $(p=0.03)$. There was a higher proportion of females among those with uncontrolled asthma than among those with controlled or partially controlled asthma (Table 1). The three groups showed no differences in terms of the presence of smokers or pets in the household (Table 1).

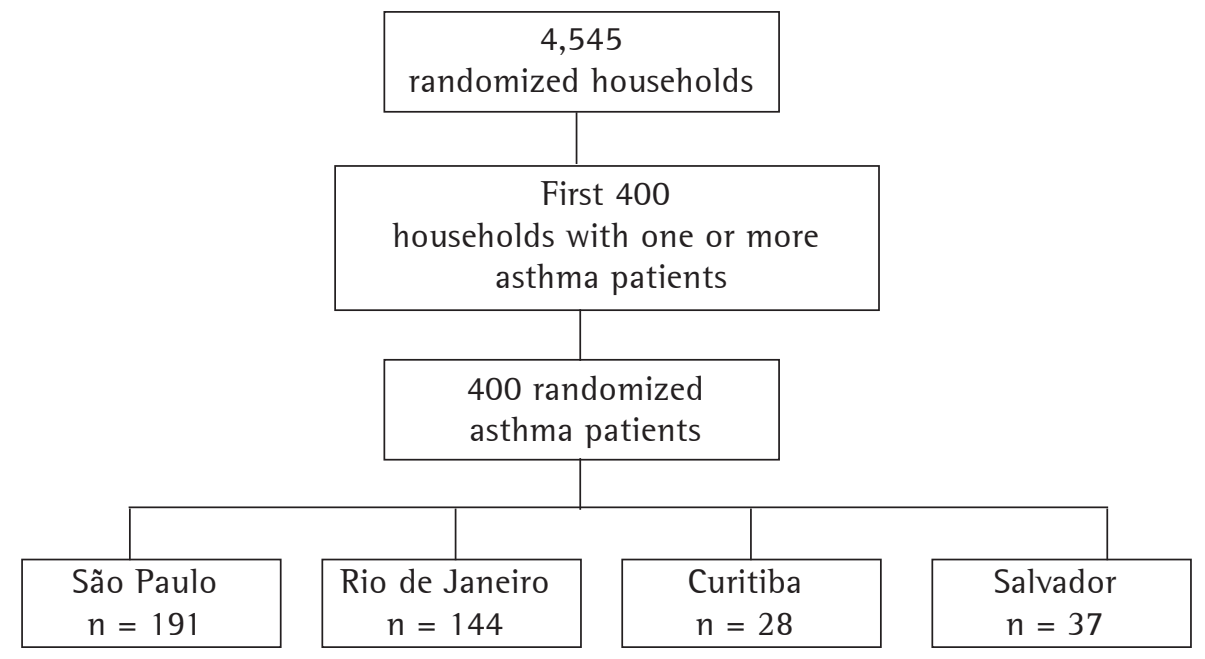

Figure 1 - Distribution of the patients eligible for the study.

Table 1 - Demographic data related to the 400 asthma respondents in Brazil. ${ }^{\text {a }}$

\begin{tabular}{lcccc}
\hline Variables & \multicolumn{3}{c}{ Asthma groups } & $p$ \\
\cline { 2 - 3 } & Controlled & Partially controlled & Uncontrolled & \\
\cline { 2 - 3 } & $(\mathrm{n}=37)$ & $(\mathrm{n}=226)$ & $(\mathrm{n}=137)$ & $0.03^{*}$ \\
\hline Age, years & $31.1 \pm 9.9$ & $38.5 \pm 16.4$ & $39.3 \pm 16.58$ & 0.02 \\
Gender, female & $24(64.9)$ & $143(63.3)$ & $105(76.6)$ & 0.59 \\
Pets in the household & $20(54.1)$ & $115(51.3)$ & $64(46.7)$ & 0.67 \\
Smokers in the household & $14(37.8)$ & $101(44.7)$ & $57(41.6)$ & $0.67)$ \\
\hline
\end{tabular}

${ }^{*}$ Controlled vs. uncontrolled. a Values expressed as $\mathrm{n}(\%)$, except where otherwise indicated. ${ }^{b}$ Values expressed as mean \pm SD. 
Table 2 - Impact of asthma on the health status of the 400 respondents. ${ }^{2}$

\begin{tabular}{lcccc}
\hline Variables & \multicolumn{3}{c}{ Asthma groups } & $\mathrm{p}^{*}$ \\
\cline { 2 - 4 } & Controlled & $\begin{array}{c}\text { Partially } \\
\text { controlled }\end{array}$ & Uncontrolled \\
\cline { 2 - 4 } & $(\mathrm{n}=37)$ & $(\mathrm{n}=226)$ & $(\mathrm{n}=137)$ & 0.05 \\
\hline Patients visiting the emergency room & $13(35.1)$ & $130(57.5)$ & $85(62.0)$ & 0.001 \\
Hospitalized patients & $3(8.1)$ & $52(23.0)$ & $54(39.4)$ & 0.3 \\
Patients admitted to the ICU & $0(0.0)$ & $13(5.8)$ & $13(9.5)$ & 0.3 \\
Patients missing work/school & $6(16.2)$ & $82(36.3)$ & $64(46.7)$ & 0.01 \\
Use of maintenance medication in the last 4 weeks & $2(5.4)$ & $45(19.9)$ & $57(49.6)$ & 0.001 \\
\hline
\end{tabular}

aValues expressed as mean $\pm \mathrm{SD}$. ${ }^{*}$ Chi-square test.

Table 3 - Impact of asthma on daily life, as determined by the score (1: high interference; 4: no interference), by level of asthma control.a,"

\begin{tabular}{|c|c|c|c|}
\hline \multirow[t]{3}{*}{ Variables } & \multicolumn{3}{|c|}{ Asthma groups } \\
\hline & Controlled & Partially controlled & Uncontrolled \\
\hline & $(\mathrm{n}=37)$ & $(n=226)$ & $(n=137)$ \\
\hline Sports/recreation & $4 \pm 0$ & $2.58 \pm 1.00$ & $2.31 \pm 0.90^{n+m+n}$ \\
\hline Normal physical exertion & $4 \pm 0$ & $2.54 \pm 0.90^{* * * *}$ & $2.12 \pm 0.80^{* \ldots+\cdots}$ \\
\hline Social activities & $3.86 \pm 0.40^{* * *}$ & $3.14 \pm 0.90^{* * * *}$ & $2.56 \pm 1.00^{* \ldots+m}$ \\
\hline Sleep & $3.62 \pm 0.50^{* * *}$ & $2.47 \pm 1.00^{* * * *}$ & $1.72 \pm 0.80^{\ldots+\cdots}$ \\
\hline Interference with life & $4 \pm 0^{* * *}$ & $2.9 \pm 1.0^{n+*}$ & $2.1 \pm 0.9^{* * * *}$ \\
\hline
\end{tabular}

aValues expressed as mean \pm SD. *Tukey's post hoc test. ${ }^{* *} p<0.001$ versus partially controlled. ${ }^{* * *} p<0.001$ versus uncontrolled. ${ }^{* * * *} p<0.001$ versus controlled.

Among the patients with uncontrolled or partially controlled asthma, the negative impact of the disease on health status was greater. This can be seen in Table 2, which shows that the numbers of patients with uncontrolled or partially controlled asthma who visited the emergency room, who were hospitalized, and who missed school or work were higher than were those of patients with controlled asthma. However, there were no differences in the number of patients admitted to the ICU. As can be seen in Table 2, the number of patients who did not receive maintenance medication in the last four weeks was very high.

Among the patients with uncontrolled or partially controlled asthma, the impact of the disease on their daily life was greater. The scores for the questions related to normal physical exertion, social activities, sleep, sports/recreation, and interference with life were (statistically significantly) lower among those with uncontrolled asthma than among those with controlled or partially controlled asthma; likewise, the scores for those same questions were lower among those with partially controlled asthma than among those with controlled asthma, except for the question related to sports/recreation, for which there was no significant difference (Table 3).

\section{Discussion}

Although current guidelines suggest that the main goal of asthma treatment is to achieve adequate disease control ${ }^{(9)}$ and to reduce future risk of exacerbations, ${ }^{(10)}$ the results of the present study demonstrate that only $9.3 \%$ of the asthma patients interviewed had controlled asthma, as determined in accordance with the GINA criteria. The proportions of patients with uncontrolled or partially controlled asthma who visited the emergency room (57.5\% and 62.0\%, respectively), who were hospitalized (23.0\% and 39.4\%, respectively), and who missed work or school (36.3\% and $46.7 \%$, respectively) were higher than were those of patients with controlled asthma. Likewise, the negative impact on sports, normal physical exertion, social activities, sleep, and quality of life was greater.

The present study had a lower proportion of subjects with controlled asthma than did the AIM survey conducted in the USA (9.3\% vs. $26.0 \%$ ). (11) One of the reasons that could explain this lower proportion than that found in the USA is poor adherence to pharmacological treatment in Brazil. A prospective one-year follow-up study involving children attending a referral outpatient 
clinic in the city of Belo Horizonte, Brazil, revealed that, of those with uncontrolled asthma, only $49.6 \%$ were adherent to treatment at 4 months of treatment, compared with $86.6 \%$ of those with controlled asthma. This generated a proportion of $62.3 \%$ of patients with clinically uncontrolled asthma, and an adherence rate of $80 \%$ to the use of medication was the cut-off point for achieving asthma control. ${ }^{(12)}$ In addition, the proportion of patients with controlled asthma found in that study was lower than that reported in a study conducted in the city of Porto Alegre, Brazil, in which $17.5 \%$ of the subjects were classified as having controlled asthma. ${ }^{(13)}$ This discrepancy observed between our findings and national data might be due to the fact that, in the study conducted in Porto Alegre, the patients attended a referral asthma outpatient clinic, unlike in our study, in which the sample was randomized and included four Brazilian cities, which should correspond more closely to what is observed in real life. It is of note that only $5.4 \%$ of the subjects with controlled asthma in our study used maintenance medication. This leads us to believe that our study subjects had very mild asthma. In addition, it is known that, in order to achieve optimal asthma control at a population level, there should be programs aimed at full treatment of patients and their comorbidities, such as allergic rhinitis. ${ }^{(14,15)}$ However, the proportion of patients with uncontrolled asthma found in our study (34.2\%) was very similar to that reported in the AIM survey conducted in the USA (30.0\%). ${ }^{(9)}$

High numbers of emergency room visits, hospitalizations, ICU admissions, and school/work absences are known to be directly related to failure to control asthma. Therefore, as expected, the proportion of patients who were hospitalized was found to be higher among those with uncontrolled or partially controlled asthma than among those with controlled asthma in the present study, ranging from $8.1 \%$ among those with controlled asthma to $39.4 \%$ among those with uncontrolled asthma. Also, as in other studies, we found that patients with uncontrolled or partially controlled asthma are at higher risk for hospitalization. ${ }^{(16-18)}$ The proportion of patients who visited the emergency room was also higher among those with uncontrolled or partially controlled asthma (57.5\% and $62.0 \%$, respectively) than among those with controlled asthma (35.1\%). High proportions of patients who visited the emergency room and of patients who were hospitalized were also found in a survey conducted in the USA, in which more than half of the patients reported having been to the emergency room for asthma, and nearly one third of the patients reported having been hospitalized for asthma at some point in their life. ${ }^{(19)}$

In addition to the clinical, functional, and psychological consequences that asthma attacks and hospitalizations have on subjects with asthma, there is the increase in the use of health resources and, consequently, in the costs of the disease. A recent study has demonstrated that subjects with uncontrolled asthma use more health resources than do those with controlled asthma. (20) In the present study, school absenteeism was higher among the patients with uncontrolled or partially controlled asthma (36.3\% and 46.7\%, respectively) than among those with controlled asthma (16.2\%); however, these values are lower than that found in the AIRLA survey, in which 58\% of the children interviewed reported having missed school because of an asthma attack. ${ }^{(7)}$ Asthma symptoms can affect activities of daily living, as well as contributing to school absenteeism. A study conducted in California, USA, found that asthma accounted for approximately 1.9 million lost school days and 2 million lost workdays in 2005. School-age children (4-17 years of age) with daily or weekly asthma symptoms were at higher risk of missing school for at least one week in the last 12 months because of their asthma (28\%) than were children who had asthma symptoms less than once a month (15\%). Adults with asthma were at risk of missing work for at least one week in the previous year because of their asthma, this risk being twice as high among those with daily or weekly symptoms (12\%) compared with those who had symptoms less than once a month (5\%). ${ }^{(21)}$ Work absenteeism is directly related to reduced productivity. Consequently, this reduction promotes an increase in the indirect costs of the disease, leading to higher costs to employers and the government.

Among subjects with uncontrolled or partially controlled asthma, the impact of asthma on daily life is greater than it is among those with controlled asthma. They report that asthma interferes with sports, normal physical exertion, social activities, sleep, and overall quality of life "a little", which 
demonstrates the importance of monitoring these patients. Many negative consequences caused by asthma could be mitigated by early diagnosis, medical care, treatment follow-up, and education programs for patients, family members, and health professionals. ${ }^{(22)}$

Education programs should be based on guidelines, should be associated with medical treatment, and should have a multidisciplinary approach. ${ }^{(2)}$ After interventions, which include education on the disease, the correct use of the medication, identification of asthma triggers, environmental prophylactic measures, and signs of good and poor asthma control, patients experience improvement in overall quality of life and its components (physical limitation, frequency of symptoms, and treatment adherence). ${ }^{(23)}$ A study on the implementation of a short-term education program for children with asthma demonstrated that the program succeeded in increasing participants' knowledge of asthma, allaying fears and correcting misconceptions about asthma treatment and control. ${ }^{(23)}$

The impact of asthma in the USA remained virtually unchanged between 1998 and 2009. There were some improvements in the identification of symptoms and symptom-related limitations, but little change occurred in asthma treatment adherence. Patients still have inadequate understanding of the meaning of adequate asthma control. ${ }^{(24)}$ Our data show that, 9 years after the AIRLA survey, only a low proportion of patients keep their asthma under control.

The method used in the present study was the same as that used in important studies, such as the AIM survey conducted in the USA and the LA AIM survey, and was similar to that used in the AIRLA survey. ${ }^{(7)}$ However, our study has some limitations. Although four important Brazilian cities were included in the present study, it is possible that they do not represent the population with asthma in Brazil. Nevertheless, it is unlikely that studies with this type of design can cover the entire population of a country. The fact that the four cities are located in different regions of Brazil can somewhat mitigate this limitation.

Another limitation of this study is that we did not have data on pulmonary function measured by spirometry, a test that is also a part of staging requirements for the definition of disease control; an $\mathrm{FEV}_{1}<70 \%$ of predicted is one of the criteria for classifying asthma as uncontrolled. However, knowing that the disease is not controlled only on the basis of the questionnaire is enough of a warning to our health care system, given that the proportion of patients was high. Finally, these data were obtained from self-reports, i.e., they were not extracted from medical records.

We conclude that approximately only $10 \%$ of the population of asthma patients in Brazil have controlled asthma, as determined in accordance with the GINA criteria. In addition, the numbers of patients with uncontrolled or partially controlled asthma who visited the emergency room and who missed work or school were higher than were those of patients with controlled asthma, and the impact of the disease on daily activities was greater among the former. Since free treatment for asthma patients is already available in Brazil, the finding that asthma is not controlled in $90 \%$ of patients implies that, in our country, asthma treatment should be monitored more closely in order to increase treatment adherence and, consequently, the level of asthma control. This can improve patient quality of life and minimize the negative impact of the disease.

\section{References}

1. Asher Ml, Montefort S, Björkstén B, Lai CK, Strachan DP, Weiland SK, et al. Worldwide time trends in the prevalence of symptoms of asthma, allergic rhinoconjunctivitis, and eczema in childhood: ISAAC Phases One and Three repeat multicountry cross-sectional surveys. Lancet. 200;368(9537):733-43. Erratum in: Lancet. 2007;370(9593):1128.

2. Sociedade Brasileira de Pneumologia e Tisiologia. Diretrizes da Sociedade Brasileira de Pneumologia e Tisiologia para o Manejo da Asma 2012. J Bras Pneumol. 2012;38(Suppl 1) S1-S46.

3. Solé D, Wandalsen GF, Camelo-Nunes IC, Naspitz CK; ISAAC - Brazilian Group. Prevalence of symptoms of asthma, rhinitis, and atopic eczema among Brazilian children and adolescents identified by the lnternational Study of Asthma and Allergies in Childhood (ISAAC) Phase 3. J Pediatr (Rio J). 2006;82(5):341-6.

4. Worldwide variations in the prevalence of asthma symptoms: the International Study of Asthma and Allergies in Childhood (ISAAC). Eur Respir J. 1998;12(2):315-35. http://dx.doi.org/10.1183/09031936.98.12020315

5. Eagan TM, Gulsvik A, Eide GE, Bakke PS. The effect of educational level on the incidence of asthma and respiratory symptoms. Respir Med. 2004;98(8):730-6. http://dx.doi. org/10.1016/j.rmed.2004.02.008 PMid:15303637

6. Ellison-Loschmann L, Sunyer J, Plana E, Pearce N, Zock JP, Jarvis D, et al. Socioeconomic status, asthma and chronic bronchitis in a large community-based study. Eur Respir J. 2007;29(5):897-905. http://dx.doi. org/10.1183/09031936.00101606 PMid:17215316

7. Neffen H, Fritscher C, Schacht FC, Levy G, Chiarella P, Soriano JB, et al. Asthma control in Latin America: the 
Asthma Insights and Reality in Latin America (AIRLA) survey. Rev Panam Salud Publica. 2005;17(3):191-7. http://dx.doi.org/10.1590/S1020-49892005000300007 PMid:15826399

8. Global Initiative for Asthma (GINA) [homepage on the Internet]. Bethesda: NHLBI/WHO; c2011 [updated 2011 Dec; cited 2012 Dec 18]. Available from: www. ginasthma.com

9. Bateman ED, Hurd SS, Barnes PJ, Bousquet J, Drazen JM, FitzGerald M, et al. Global strategy for asthma management and prevention: GINA executive summary. Eur Respir J. 2008;31(1):143-78. http://dx.doi. org/10.1183/09031936.00138707 PMid:18166595

10. Bateman ED, Reddel HK, Eriksson G, Peterson S, Ostlund 0 , Sears MR, et al. Overall asthma control: the relationship between current control and future risk. J Allergy Clin Immunol. 2010;125(3):600-8, 608.e1-608.e6.

11. Gold LS, Smith N, Allen-Ramey FC, Nathan RA, Sullivan SD. Associations of patient outcomes with level of asthma control. Ann Allergy Asthma Immunol. 2012;109(4):260-5. http://dx.doi.org/10.1016/j. anai.2012.07.024 PMid:23010232

12. Lasmar L, Camargos P, Champs NS, Fonseca MT, Fontes MJ, Ibiapina C, et al. Adherence rate to inhaled corticosteroids and their impact on asthma control. Allergy. 2009;64(5):784-9. http://dx.doi.org/10.1111/j.13989995.2008.01877.x PMid:19183166

13. Dalcin PT, Menegotto DM, Zanonato A, Franciscatto L, Soliman F, Figueiredo M, et al. Factors associated with uncontrolled asthma in Porto Alegre, Brazil. Braz J Med Biol Res. 2009;42(11):1097-103. http://dx.doi. org/10.1590/S0100-879X2009005000035 PMid:19820883

14. Cruz AA, Souza-Machado A, Franco R, Souza-Machado C, Ponte EV, Moura Santos P, et al. The impact of a program for control of asthma in a low-income setting. World Allergy Organ J. 2010;3(4):167-74. http://dx.doi. org/10.1097/WOX.0b013e3181dc3383 PMid:23268428 PMCid:PMC3488909

15. Fontes MJ, Affonso AG, Calazans GM, de Andrade CR, Lasmar LM, Nader CM, et al. Impact of an asthma management program on hospitalizations and emergency department visits. J Pediatr (Rio J). 2011;87(5):412-8. http://dx.doi.org/10.2223/JPED.2129
16. Pereira ED, Cavalcante AG, Pereira EN, Lucas P, Holanda MA. Asthma control and quality of life in patients with moderate or severe asthma. J Bras Pneumol. 2011;37(6):705-11. PMid:22241026

17. Allegra L, Cremonesi G, Girbino G, Ingrassia E, Marsico S, Nicolini G, et al. Real-life prospective study on asthma control in ltaly: cross-sectional phase results. Respir Med. 2012;106(2):205-14. http://dx.doi.org/10.1016/j. rmed.2011.10.001 PMid:22035853

18. Lai CK, Ko FW, Bhome A, DE Guia TS, Wong GW, Zainudin BM, et al. Relationship between asthma control status, the Asthma Control Test ${ }^{\mathrm{TM}}$ and urgent health-care utilization in Asia. Respirology. 2011;16(4):688-97. http://dx.doi. org/10.1111/j.1440-1843.2011.01954.x PMid:21362102

19. Meltzer EO, Blaiss MS, Nathan RA, Doherty DE, Murphy KR, Stoloff SW. Asthma burden in the United States: results of the 2009 Asthma lnsight and Management survey. Allergy Asthma Proc. 2012;33(1):36-46. PMid:22309770

20. Santos LA, Oliveira MA, Faresin SM, Santoro IL, Fernandes AL. Direct costs of asthma in Brazil: a comparison between controlled and uncontrolled asthmatic patients. Braz J Med Biol Res. 2007;40(7):943-8. http://dx.doi.org/10.1590/ S0100-879X2006005000129 PMid:17653447

21. Meng YY, Babey SH, Hastert TA, Lombardi C, Brown ER. Uncontrolled asthma means missed work and school, emergency department visits for many Californians. Policy Brief UCLA Cent Health Policy Res. 2008;(PB2008-2):1-8.

22. Costa Mdo R, Oliveira MA, Santoro IL, Juliano Y, Pinto JR, Fernandes AL. Educational camp for children with asthma. J Bras Pneumol. 2008;34(4):191-5. PMid:18425254

23. Bettencourt AR, Oliveira MA, Fernandes AL, Bogossian M. Educação de pacientes com asma: atuação do enfermeiro. J Pneumol. 2002;28(4):193-200. http:// dx.doi.org/10.1590/S0102-35862002000400004

24. Nathan RA, Meltzer E0, Blaiss MS, Murphy KR, Doherty DE, Stoloff SW. Comparison of the Asthma in America and Asthma Insight and Management surveys: did asthma burden and care improve in the United States between 1998 and 2009? Allergy Asthma Proc. 2012;33(1):6576. PMid:22309828

\section{About the authors}

\section{Mariana Rodrigues Gazzotti}

Professor. Federal University of São Paulo/Paulista School of Medicine and São Camilo University Center, São Paulo, Brazil.

\section{Oliver Augusto Nascimento}

Attending Pulmonologist. Federal University of São Paulo/Paulista School of Medicine, São Paulo, Brazil.

\section{Federico Montealegre}

Medical Director. Merck, Sharp \& Dohme Corp., Carolina, PR, USA; and Professor. School of Public Health, University of Puerto Rico, Reio Piedras, PR, USA

\section{James Fish}

Global and Scientific Affairs. Merck, Sharp \& Dohme Corp., Whitehouse Station, NJ, USA.

\section{José Roberto Jardim}

Tenured Professor of Pulmonology, Federal University of São Paulo/Paulista School of Medicine, São Paulo, Brazil. 